\section{Economics of climate change}

SIR - Further to your news report on the economics of climate change (Nature 378, $119 ; 1995)$, I write on behalf of myself and the undersigned*. We note that the Intergovernmental Panel on Climate Change (IPCC) is now due to approve for publication its full Second Assessment Report (SAR) at its plenary meeting in Rome on 11-15 December.

The assessment by Working Group Three (WG3) of the "Social Costs" of climate change (or "damages") will be included in the SAR. This contains the now notorious 15:1 mortality costing between rich and poor people in developed and developing countries. This largely explains why the overall damage figures cited in the chapter (1.5-2 per cent of gross world product) are so low.

Both the global and the regional damage figures are widely regarded as unsafe, so much so that the Summary for PolicyMakers (SPM) of the "Social Costs" written by the governmental representatives at the last WG3 meeting omits reference to these quantitative damage results altogether.

In fact, rather than being a 'summary' of the chapter, the SPM largely concentrates its comments on how much higher the damage results would have been had nondiscriminatory methods of valuation been used. This has produced a marked inconsistency between the chapter and its summary, which the authors of the chapter themselves have confirmed.

If IPCC puts its imprimatur on this material by publishing it, this unsafe and discriminatory data will become official advice to the UN negotiating process for at least the next five years. This would give

\footnotetext{
*Tom Wakeford (Biology, York); Nigel Woodcock (Earth Sciences, Cambridge); Gerald Leach (Stockholm Environment
Institute and IPCC lead author); John Whitelegg (Ecologica UK); Ben Matthews (East Anglia); Maneka Gandhi (ex-Environment Minister, India); Vandana Shiva (Centre for Science and Ecology); Bittu Sehgal (Sanctuary Magazine); Medhar Paktar: Claude Alvarez (Third World Network, India); Peter Newell (Environmental Politics, Keele): David Smernoff (Bay Area

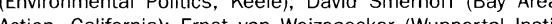
ute); Christine von Weizsaecker; Hans Peter Duerr (Max Planck Institute for Physics); Freda Meissner-Blau (ECOROPA); Charles Levenstein (Massachusetts and New Solutions); Brian Moss (Environmental and Evolutionary Biology, Liverpool); George Marshall (Earth Action Resource Centre); John Barkham (Environmental Sciences, East Anglia); Nicholas Hildyard (The Ecologist); Rudolf Lippe (World Decade for Culural Understanding, UNESCO); Hartwig Spitzer (Center for Science and International Security, Hamburg); Hans Jurgen Fischbeck (International Network of Engineers and Scientists for Global Responsibility); Heinrich Volkert (Protestant Church of Germany): Simon Naylor (Geography, Keele); Martin Rees (Kings College Cambridge); Philip Webber (Scientists for Global Responsibility); Michael Benfield (Town and Country Planling University of New (Wuppertal Institute); Angelika Zahrnt (BUND/ Friends of the Earth, Germany); Greg Samways (Environmental Sciences, East Anglia); Susan George (Transnational Institute, Amsterdam); Andrew McLellan (Institut für Umwelt-wissenschaften, Zurich); Philip Smith (International Network of Engineers and Scientists for Global Responsibility); Christian Azar (Chalmers University of Technology, Goteborg); KarlErik Eriksson (TheoUniversity of Technology, Gote.r. R); Kar Erk Eriksson (Theoretical Physics, Goteborg); P. R. Shukla (Indian Institute of Management, Ahmedabad and IPCC WG3 lead author); Tim Lenton (Environmental Sciences, East Anglia, and Plymouth
} Marine Laboratory). a disastrously wrong signal at a time when it is becoming increasingly clear that serious policy measures to arrest climate change are now required and when the political tensions over the "differentiated responsibilities" in this task are increasing as well.

Moreover, if the IPCC goes ahead and publishes in these circumstances, it will violate its own procedures. These clearly state that approval of the SPM signifies that it is "consistent with the factual material contained in the full scientific and technical assessment," and this is clearly not the case.

In these circumstances, IPCC's reputation for procedural correctness and consensus-building around scientific accuracy will be permanently compromised. Consequently we urge the rejection of the "Social Costs" chapter in the report.

\section{Aubrey Meyer}

Global Commons Institute (GCl),

42 Windsor Road

London NW2 5DS, UK

Fax $+44(0) 1818302366$

e-mail saveforests@gn.apc.org

\section{Finding fault}

SIR - The intensity and duration of ground shaking at a site depends not only upon the magnitude of the earthquake but also upon its distance; therefore the statement that the Very Large Telescope being constructed on Mount Paranal in northern Chile was designed to withstand earthquakes of at least magnitude 8.5 is incomplete.

The building that will house the telescope is under construction and the earthquake of 8-magnitude on 30 July "seems to have caused little damage ... although damage to the shock-absorbing columns will require several weeks to repair" (Nature 376, 542; 1995). A magnitude 6.5 earthquake close to the site can produce ground shaking much more intense, but of shorter duration, than a magnitude 8.5 at a greater distance. The epicentre of this earthquake was $130 \mathrm{~km}$ south of the site of the telescope so it raises questions about the seismic design of the building, and of the telescope itself. If it has not already done so, the European Southern Observatory would be well-advised to seek the advice of an expert in earthquake engineering and strong ground shaking, as well as a geologist who can identify potentially active faults in the vicinity.

\section{George W. Housner}

\section{Thomas Laboratory,}

California Institute of

Technology,

Pasadena, California 91125, USA
Theism and science

SIR - I agree with Walter Gratzer's comment in his review of John Carey's The Faber Book of Science (Nature 378, 111-112; 1995) that theology can hardly "be regarded as a science", although it is none the worse for that, as neither can poetry or music. But Gratzer's further claim that " $t]$ he cast of mind that draws scientists to their profession is the antithesis of that which predisposes towards religion" is inaccurate. Apart from the well documented contributions of theists to the scientific enterprise, in particular since the founding of the Royal Society in the seventeenth century, there is clear evidence of a contemporary 'selection pressure' so that Christians tend to be more abundant in the sciences than the arts.

This has often drawn comment here in Cambridge, where scientists are far more abundant in the packed central city churches than those from the arts. A possible source of this 'selection pressure' is the shared scepticism of both Christians and scientists towards the more extreme forms of relativism promoted by postmodernism, and their common 'realist' stance which maintains that neither scientific nor religious knowledge is a merely social construct.

It would be of interest to know whether this disparity in the representation of Christians in the sciences rather than the arts is a Cambridge phenomenon only, or whether it reflects some wider trend.

\section{Denis R. Alexander}

Babraham Institute,

Babraham Hall,

Babraham,

Cambridge CB2 4AT, UK

\section{Gloves off}

SIR - In a recent leading article "Time to ban British boxing" (Nature 377, 561-562; 1995 ), you correctly predicted the reaction of the House of Commons to suggestions of a ban. In particular, the arguments for a ban on the grounds of the neurological damage to boxers and the degrading effect on society, were insufficient to counter the libertarian views of the supporters of boxing.

As boxing is not to be banned, perhaps the neurological damage to boxers could be limited by banning the use of gloves or any other protective device and declaring the winner to be the first to draw blood. This would result only in relatively superficial cuts and bruises instead of the present prolonged battering of the skull, with its consequent trauma to the brain. Promoters would also benefit from the increased audiences.

Andrew J. Wilson

49 Avenue du Mistral,

1200 Brussels, Belgium 